\title{
Main Influence of the Chinese Language on English Learners
}

\author{
Qiujuan Zhu \\ College of Foreign Language, Wuhan University of Science and Teaching, Wuhan 430065, China \\ Email: zqj7665@sina.com
}

\begin{abstract}
This thesis focuses on how the Chinese language influences English learners, which will help English learners to recognize their difficulties in English learning and know how to break away interference from their native language.
\end{abstract}

Index Terms - the English language, the Chinese language, discourse, syntax, lexicon

\section{INTRODUCTION}

The L1 (Chinese) influence on 12 (English) learning catches great attention of language teaching expertise in China. Much of research has be done on how the Chinese language having an impact on English learners. Guo Cui (2001) generalizes the development of the studies of language transfer on the basis of Behaviorism, Universal Grammar and Cognitivism, makes an analysis of language transferability and characterization of language transfer and concludes by pointing out the implications of the studies of language transfer to English teaching. Guo Chunjie and Liu Fang (1997) offer a cognitive framework for explaining L1 (Chinese) influence on L2 (English) learner's thinking operations during L2 production. In the study, they apply Think Aloud (TA) to detect what is going on in the mind without significant interference from outside. In conclusion, they point out that: (1) L1 (Chinese) influence plays a more significant role in L2 (English) production than traditionally supposed; (2) L1 influence on L2 production is largely covert, it lies in the high-level cognitive operations in language production. Thus, Chinese influence on English learners is inevitable and primarily manifests itself on syntax and lexical usage, as the following will illustrate.

\section{MAIN INFLUENCES ON DisCoURSE PATTERNS}

Different thought patterns of English and Chinese inexorably cause the distinctions of their discourse structures. However, most Chinese students are not aware of it. They usually comply the discourse structures of their native language to develop English ones, which will bring about faults in discourse construction. The following test will provide a more or less support about it.

The test designed by E. O. Winter in 1976 is used to examine students' competence of English discourse construction. The test requires students to put 10 disrupted sentences into proper order.

A Comparison of Two National Approaches to the Problem of 1ce Roads:

(1) In English, however, the tungsten-tipped spikes would tear the thin tarmac surfaces of our roads to pieces as soon as the protective layer of snow or ice melted. (2) Road maintenance crews try to reduce the danger of skidding by scattering sand upon the road surfaces. (3) We therefore have to settle for the method described above as the lesser of two evils. (4) Their spikes grip the icy surfaces and enable the motorist to corner safely where non-spiked tyres would be disastrous. (5) Its main drawback is that if there are fresh snowfalls the whole process has to be preheated, and if the snowfalls continue, it becomes increasingly ineffective in providing some kind of grip for tyres. (6) These tyres prevent most skidding and are effective in the extreme weather conditions as long as the roads are regularly cleared of loose snow. (7) Such a measure is generally adequate for our very brief snowfalls. (8) Whenever there is snow in England, some of the country roads may have black ice. (9) In Norway, where there may be snow and ice for nearly seven months of the year, the law requires that all cars be fitted with special steel spiked tyres. (10) Motorists coming suddenly upon stretches of black ice may find themselves skidding off the road.

The students examined: 57 college students who major in international trade and law in their second years.

The standard examined: According to the evaluating standard of E. O. Winter, it is considered not to pass the test if there are four or more than four errors. In addition, if the first or last sentence is chosen incorrectly, it also is considered an error .The following is the statistics.

TABLE1.

ERROR RATE FOR DISCOURSE CONSTRUCTION

\begin{tabular}{|c|c|c|c|}
\hline Students & Unpassing\% & Error in the first sentence\% & Error in the last sentence\% \\
\hline 57 & 92.59 & 96.29 & 29.62 \\
\hline
\end{tabular}

The statistic data displays that student's competence of discourse construction is poor. The cause might be that 
students are unfamiliar with the features of English discourse. This essay is the general-particular pattern which moves from a general statement about the subject to a detailed discussion that provides specific evidence, examples, and analysis to support or elaborate upon the general statement. So, developing this organizational pattern, the general statement should be put in the beginning. Having less knowledge on English general-particular pattern, most students don't know which sentence is the embodiment of degree of generality and put sentence 9 by mistake in the beginning instead of sentence 8 . As a result, most of them didn't pass the test.

\section{MAIN INFLUENCE ON SYNTAX}

Syntax refers to the rules of grammar, which can be used for ordering and connecting words in a sentence. The syntactic unit is one of the importances in any language structure, because at this level communication may be realized. The English sentence centers around the verb and it may be formulated as below.

$\mathrm{S}$ (sentence) $=\mathrm{Nph}($ Noun Phrase $)+$ Vph (Verb Phrase)

"Some of the modern Chinese grammarians, basing themselves on the analysis of the Chinese structure and the description of the Chinese sentences, hold that a Chinese sentence is based on two parts: THEME and RHYME. By 'theme', they mean the topic; and by 'rhyme', they mean the comment" (Xiao Liming, 2002:106). So comes the general formula:

$\mathrm{S}$ (sentence) $=\mathrm{T}$ (heme) $+\mathrm{R}$ (hyme)

English is a subject-prominent language, while Chinese is a topic-prominent language. But not all topics mean subjects. In Longman Modern English Dictionary, the definition of subject refers to a noun, noun phrase, or pronoun that comes before a main verb and represents the person or thing that performs the action of the verb or about which something is stated. So, in English, only noun, noun phrase and pronoun can be used as subject. In Chinese, almost every part of speech can be used as subject, including noun, verb, adjective, adverb, phrase, etc.

For example:

1. 等待不能解决问题. (a verb as subject)

2.我这几天不休息没关系。(A phrase of subject-predicted as subject)

3.开创新局面是我们的共同任务。 (A phrase of verb-object as subject)

4.太慢了不好，太急了也不好。(Adjective as subjects) (quoted in Xiao Liming, 2000:97)

The differences in syntactical structures of English and Chinese lead to difficulties for language learners to have a good mastery of the norms of English sentences. In speech and writing there are two types of errors especially likely to arise from differences in Chinese and English: (1) substitutions, (2) calques of structures. Substitutions involve a use of native language forms in the target language, for example the following sentences. Here, F stands for false English sentences written by our students; T stands for true English sentences.

F. In the college study is our dream. (A prepositional phrase as subject)

T. Studying in the college is our dream.

F. Too easy or too difficult is no good for us (Adjectives as subjects)

T. The books, which are too easy or too difficult, are no good for us.

Calques are errors that reflect very closely a native language structure. The following sentences are written by our students.

(1) I felt study of graduate is very busy.

我感到本科生的学习非常忙。

(2) I have a healthy body and clever head.

我有健康的身体和联明的脑袋。

(3)His body looks well.

他的身体看上去很好。

A longer subject is one of taboos in English syntactical structure. In order to avoid it, a formal subject "it" is used to replace the real subject, which is the most difficult pattern for Chinese students to master and apply, because there doesn't exist the phenomena in Chinese for example the following sentences. Here, F also stands for false English sentences written by students; T stands for true English sentences.

F. I know study is very hard.

T. I know it is a hard job to study.

F. The factory produces them isn't a difficult thing.

T. It isn't difficult for the factory to produce them.

Odlin (1989:37) indicates that if learners sense that particular structures in the target language are very different from counterparts in the native language, they may try to avoid using those structures. The attributive usage modes in English are a case in point. In Longman Modern English Dictionary, the definition of attributive is of an adjective, noun or phrase to describe and come before a noun. Generally speaking, there are three modes between the attributive modifiers and head terms, that is (a) the attributive modifier $\rightarrow$ the head word; (b) the attributive modifier $\rightarrow$ the head word $\leftarrow$ the attributive modifier; (c) the head word $\longleftarrow$ the attributive modifier. In the three modes, only mode (a) is an obvious correspondence between English and Chinese, for example, thunderous applause (雷鸣般的掌声), convincing remarks 
(掷地有声的话语), splendid opportunity (绝妙的机会), etc. But, to the later two modes, it is difficult for students to learn and apply them. It is estimated that more than 50 percent college students try to avoid using or to use fewer those modes.

\section{Main Influence ON LeXICAL Usage}

The English language is orthographic spelling; while the Chinese language is ideographic character. They are different in word formation, morphology and in lexical usage. The prominent characteristics of English lexicon are its inflectional change. For instance, the simple word "sign", means "a mark", now you add an affix to that word and you get signify, "to make a mark". Next you add another affix, and you arrive at significant "making a mark". Now you add a prefix for a change and you have insignificant, "making no mark". Finally you add another suffix, and you come out with insignificance, "the making of no mark". What did you do? You took a simple noun, and made it successively into a verb, an adjective, and another adjective and again a noun. It is the inflection that not only enriches the English terms but also transfers some concrete terms into abstract ones. For example, some adjectives and verbs are changed into abstract nouns such as happiness, humility, occupation, movement, etc. by adding affixes. These abstract nouns are extensively used in the English language. But, the Chinese lexicon has no inflectional change. Lian Shuneng indicates that in Chinese dictionary, it is difficult for us to seek for a precise Chinese word whose meaning can equate definitely to an abstract English noun which is transferred from an adjective or a verb (1993:501). So, English word "realization" can be translated into many concrete nouns and verbs in Chinese like “实现”, “认为”, “认清”, “了解”, “体会”, “领 悟”, “变卖”, “换取”, etc. The difference in lexicons of English and Chinese frequently causes students' errors in translating. For example:

In handling the materials of history, each act of selection is also an act of judgment.

在处理历史资料时, 每一次选择的行为都是一次判断。

In this case, students make mistakes because they don't know that in English, some abstract nouns imply the meanings of verbs, which usually should be translated into Chinese in verbs. So, the correct translation of this sentence is like this:

在处理历史资料时，每选一项资料就是作出一种判断。

\section{CONCLUSION}

Generally speaking, Chinese influence on English learners is inevitable. The cause might be that Chinese students know less the similarities and dissimilarities of the English language and the Chinese language. This has consequently. So, it is very imperative for English teachers to draw a detailed comparison on English and Chinese in their teaching, which will help learners to break away interference from their native language.

\section{REFERENCES}

[1] Ellis, R. (1985). Understanding second language Acquisition. Oxford University Press.

[2] Guo Cui. (2001). Language Transfer Study in Second Language Acquisition. TIANJIN Foreign Studies University JOURNAL, (2).

[3] Guo Chunjie \& Liu Fang. (1997). Dynamic Study of L1 Influence in Foreign Language Writing. Modern Foreign Language (4).

[4] Lian Shuneng. (1993). Contrastive Studies on English and Chinese. High Education Press.

[5] Odlin, T. (1989). Language Transfer. Cambridge University Press.

[6] Watson, O. (1974). Longman Modern English Dictionary. English, Hazell Waton \& Vinty Ltd.

[7] Xiao Liming. (2002). English-Chinese Comparative Studies \& Translation. Shanghai Foreign Language Education Press.

Qiujuan Zhu was born in Zhu Zhou, Hu Nan, China in 1964. She received her M.A degree in Linguistics and Literature from Chinese Central Normal University, China in 2005. She is currently an associate Professor in the School of Foreign Language, Wu Han University of Science and Technology, Hu Bei, China. Her research interests include theory and practice of teaching methodology. 